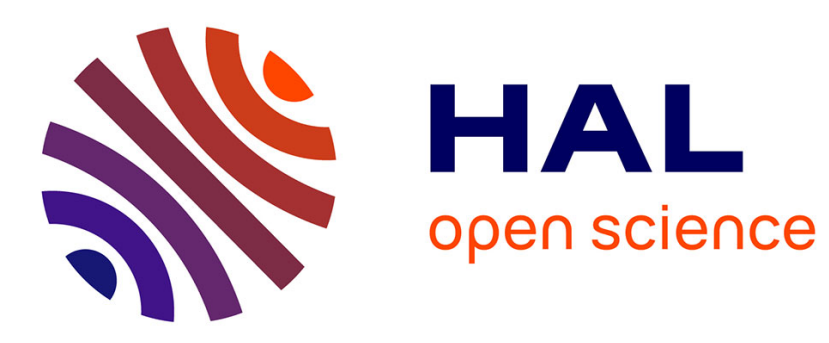

\title{
Scaling a Model of Teacher Professional Learning - Harnessing MOOCS to Recreate Deep Learning Conversations
}

Deirdre Butler, Margaret Leahy, Michael Hallissy, Mark Brown

\section{- To cite this version:}

Deirdre Butler, Margaret Leahy, Michael Hallissy, Mark Brown. Scaling a Model of Teacher Professional Learning - Harnessing MOOCS to Recreate Deep Learning Conversations. 11th IFIP World Conference on Computers in Education (WCCE), Jul 2017, Dublin, Ireland. pp.149-160, 10.1007/9783-319-74310-3_17. hal-01762875

\section{HAL Id: hal-01762875 \\ https://hal.inria.fr/hal-01762875}

Submitted on 10 Apr 2018

HAL is a multi-disciplinary open access archive for the deposit and dissemination of scientific research documents, whether they are published or not. The documents may come from teaching and research institutions in France or abroad, or from public or private research centers.
L'archive ouverte pluridisciplinaire HAL, est destinée au dépôt et à la diffusion de documents scientifiques de niveau recherche, publiés ou non, émanant des établissements d'enseignement et de recherche français ou étrangers, des laboratoires publics ou privés.

\section{(c)(1)}

Distributed under a Creative Commons Attribution| 4.0 International License 


\title{
Scaling a Model of Teacher Professional Learning - Harnessing MOOCS to Recreate Deep Learning Conversations
}

\author{
Deirdre Butler ${ }^{1}$, Margaret Leahy ${ }^{2}$, Michael Hallissy ${ }^{3}$, Mark Brown ${ }^{4}$ \\ ${ }^{1}$ Institute of Education, Dublin City University, Ireland, ${ }^{2}$ Institute of Education, \\ Dublin City University, Ireland, ${ }^{3}$ H2 Learning, Dublin, Ireland, ${ }^{4}$ National Institute \\ for Digital Learning, Dublin City University, Ireland \\ deirdre.butler@dcu.ie
}

\begin{abstract}
This paper describes the most recent phase of an innovative model of teacher professional learning that has evolved over a decade (2006 to 2016). Building on the experiences of implementing this face-to-face model, the paper reports on the most recent phase which attempts to harness the emergence of a 4th wave of online learning. The initiative involves the design and development of a Massive Open Online Course (MOOC) that potentially enables the massive scaling up of access to this already validated model of teacher professional learning designed to shift teachers' pedagogical orientations through school focussed, job embedded teacher professional learning. The importance of maintaining key elements, threshold concepts and signature pedagogies in the design of MOOCs for teacher professional learning are discussed. The paper also explores some of the challenges and potential opportunities different MOOC delivery models offer for sustaining the types of collaboration, rich dialogue and ongoing reflection observed in earlier phases of the project.
\end{abstract}

Keywords: Teacher education, $21^{\text {st }}$ century skills, online learning, MOOCs

\section{Introduction}

There is growing consensus among education leaders and researchers that both teaching and learning need to change to help students develop the skills they need to succeed in the 21st century (e.g. Ananiadou \& Claro, 2009). Stated goals for the development of "21st century skills" include critical thinking and problem-solving, communication, collaboration, self-regulation, information management and the ability to use digital technology effectively and reflectively (e.g. ETA, 2010; OECD, 2005, Binkley, Erstad, Herman, Raizen, Ripley, Miller-Ricci \& Rumble, 2012) have become commonplace in many countries. Despite this, teachers rarely have access to specific guidance or sufficient support on how to develop these skills in the classroom. Faced with this reality, the challenge is how to design professional learning experiences for teachers that enable them, in turn, to design learning activities so that their students can develop the dispositions, skills and competencies that are required to live and thrive in this complex, globally connected world of the 21st century. Against this backdrop, this paper describes an innovative model of 
teacher professional learning that has evolved over a decade (2006 to 2016). It begins by describing the professional learning model for teachers which was designed and developed in a single secondary school (Phase 1) before being expanded district wide (Phase 2). The impact of this job-embedded progamme is outlined indicating the shift in pedagogical orientation and the resulting student learning. It then explores how this face-to-face model of professional learning can be successfully reconfigured in an online environment to help scale up the initiative while also being mindful of the importance of maintaining key elements, threshold concepts and signature pedagogies in the design and development of the scalable model.

\subsection{Background and context: Teacher Professional Learning Framework}

Originating in Microsoft's 'Innovative Schools Programme' (ISP), the focus of phase 1 was to design a framework for the teacher professional learning in an Irish secondary school to integrate digital technologies into teaching and learning. This approach was considered particularly important in Ireland because rigid state standards and a traditional exam-based system of education at secondary level constrain teachers' ability to change their instructional practices. It leaves them with little time or flexibility to introduce new ideas or practices.

In developing a framework for teacher professional learning, the lead authors (Butler \& Leahy) realised the need not only to work closely with teachers and school management but also the necessity to concentrate on the teachers' beliefs and values as the starting point. This was based on research evidence that teachers' pedagogical orientations are a dominant factor in how they choose to use (or not) new technology in their classroom (e.g.; Law \& Chow, 2008; Shear, Gallagher \& Patel, 2011). It follows from this line of research that professional learning programmes are most effective when:

(i) they are embedded into teachers' professional lives and communities within the school (National Foundation for the Improvement of Education, 1996),

(ii) are focused explicitly on local goals for student learning (e.g. DarlingHammond, 1993), and

(iii) grounded in collective discussions of classroom practice (Warren Little, 2003).

Previous experience in developing a model of professional learning had also led to the realisation that to change classroom practice, teachers need to ask questions about their existing classroom practices (Butler, 2004). To this end, key features of the professional learning programme were that it was directly related to the teachers' stated needs and experiences, anchored in the meaningful context of their own classroom practices and teachers were challenged to question their practice. The Learning Activity/Student Work (LASW) framework developed by Stanford Research Institute, as part of the ISP (Shear, Means, Gorges, Toyama, Gallagher, Estrella \& Lundh, 2009), was the catalyst which enabled the teachers to design learning activities in which they embedded 21st century learning principles, develop the meta-language used to describe such learning environments and reflect on their teaching and the assignments they set their students (Butler \& Leahy, 2009, 2011). Finally, the programme was directly linked to a university postgraduate accreditation process. 
Building on the success of Phase 1, the initiative was expanded to district level in Phase 2 to work with targeted group of teachers as peer coaches to support innovative and emerging new pedagogies and technologies to facilitate student learning and the development of $21^{\text {st }}$ century skills. Management also requested that formal accreditation would continue to be a feature of the programme. In response, the Digital Learning Peer Coaching (DLPC) programme was developed (c.f. Butler \& Leahy, 2015).

\subsection{Impact of the Professional Learning Framework}

Across Phase 1 and 2, teachers, school leaders and management initially tended to view digital technologies as tools to support traditional practice. However, through participation in the programme, their understanding shifted and they began to perceive new technologies as tools that facilitate more progressive classroom practices and the development of their students' $21^{\text {st }}$ century skills (Butler \& Leahy, 2015) This was evident by the emergence of the following trends in classroom practices:

- $\quad$ Student-centred learning

- $\quad$ Project based learning rather than discrete lesson plans

- Students working collaboratively in groups rather than individual learning

- Focus on learning not on subject "content"

- Awareness of / designing lessons with opportunities for students to develop 21st century skills

- Increase in teacher confidence to use a greater range of pedagogical strategies / digital technologies

- Collaboration across and between subject departments / ripple effect

The shift in pedagogical orientation along with increased use of digital technologies in learning and teaching had a positive impact on student learning, resulting in learners:

- $\quad$ taking control of their own learning

- having greater ownership of the learning activities

- demonstrating more engagement / participation

- increased collaboration

- $\quad$ being active rather than passive in their learning

- $\quad$ taking on new leadership roles

\subsection{Problems of Scalability}

Although the developments and findings outlined above were encouraging, the issue of scalability has become increasingly problematic. Policy decisions in relation to the development of a range of "21st century skills" (NCCA, 2009) as well as the ability and the need to use digital technology effectively and reflectively in schools in Ireland, has led to ongoing demands to extend this model of professional learning. In particular, the launch of the Digital Strategy (DES, 2015) in Ireland identified "a need to ensure that ALL teachers are equipped with the knowledge, skills and confidence to integrate ICT into their practice” (p. 7). As a 
way of addressing the issue of scalability, the possibility of using an innovative MOOC format was considered in the wider context of the emergence of a $4^{\text {th }}$ wave of online learning (Picciano, 2014) which builds on the principles and foundations of blended learning.

\section{Scaling the Model of Professional Learning: MOOC related literature}

The research literature to date suggests that MOOCs have been most successful for those learners who already hold an undergraduate college degree or higher (e.g. Ebben \& Murphy, 2014). While MOOC completion rates are low, prior level of schooling is a predictor of achievement in MOOCs (Greene, Oswald, and Pomerantz, 2015); thus suggesting that teachers completing a MOOC for professional learning might be more likely to complete it than other participants (Hodges et. al., 2016). In fact, Lauillard (2016) considers the use of a MOOC as a medium for the continuing professional learning of teachers as "a perfect fit" (p. 7).

\subsection{Why a MOOC?}

Although there are issues around completion and accreditation, MOOCs are now recognised as a valid form of professional learning in a number of professions. For example, in Ireland the Law Society in 2014 was the first professional body to successfully implement a MOOC with over 2000 participants as part of a formal professional learning programme. Since then, MOOCs have demonstrated their potential to attract large numbers of learners, particularly highly qualified professionals to participate in free education programmes (Laurillard, 2016).

MOOCs can be defined as "typically involving structured and sequenced teacherled activities (e.g. videos, readings, problem-sets) coupled with online assessments and usually some venue for student interactions such as a discussion forum" (Greene et al., 2015, p.927). This typical and dominant form of MOOC is usually described as an xMOOC (Downes, 2012). In contrast, MOOCs which emphasise connecting with learners through blogs and forums rather than on structured resources are referred to as cMOOCs (McGreal et al., 2013 in Jobe, Ostlund \& Svensson, 2014). They are designed so that learners can learn "through practice (construction and responding to feedback), discussion (comments and conversations) and production (negotiating an output for evaluation by others), making it a complex and valuable learning process" (Laurillard, 2016; p. 16). The challenge in the tradition of a cMOOC is therefore to design learning experiences that support large numbers of teachers to engage in a model of co-learning, which as stated by Avalos (2011), involves:

networking and interchanges among schools and situations and is strengthened in formalised experiences such as courses and workshops that introduce peer coaching or support collaboration and joint projects ...the lesson learned is that teachers naturally talk to each other, and that such talk can take on an educational purpose (cited in Laurillard, 2016; p.3).

However, the challenge is how do you design and enable opportunities for large numbers of teachers to talk purposefully to one another online? 


\subsection{Can we recreate deep learning conversations live online?}

Much of the study of interaction in online and distance education contexts has to date primarily focused on asynchronous communication, such as forums (written discussions) (e.g. Blanchette, 2011). This research has found that asynchronous is valuable for considered discussion, where people have time to reflect and then respond. There is relatively little research conducted on synchronous oral discussions (Park \& Bonk, 2007). Therefore, the question if deep discussions can be facilitated using synchronous online learning tools is still an emerging area in the literature. What we do know is that, all too often, such live sessions have been found to be overly teacher directed (Hallissy, 2014) and lacking meaningful interaction between the tutor and learners and between learners.

Recent technological advancements can support many activities which have the capability to enhance discussion including document sharing, editing LiveChat, and online polls. Nevertheless, we are still unsure if or how these tools can most effectively facilitate deep discussion and/or if there is a need for additional technologies to enable us to 'recreate' the live classroom space online. What we do know is that interaction is essential to meaningful online learning (Abrami et al., 2011, p. 1246). Such interaction is defined by Bannan-Ritland (2002) as a

two-way communication among two or more people within a learning context, with the purposes either task/instructional completion or social relationship-building, that includes a means for teacher and learner to receive feedback and for adaptation to occur based upon information and activities with which the participants are engaged ( $p .6)$.

There is also need to be mindful, "that frequency does not equal quality" (Hirumi, 2002; p. 156 citing Northrup, 2001) and as noted by Garrison \& Cleveland-Innes (2005) "interaction does not necessarily translate into critical discourse and the integration of ideas into meaningful constructs" (p. 144). Issues such as the leadership role of the tutor, their pedagogical beliefs and disposition must also be taken into account.

Laurillard (2002) and Garrison \& Cleveland-Innes (2005) place a high value on the leadership role of the tutor in "triggering" discussion and structuring the interaction to sustain interactions. While the affordances of synchronous online learning tools do matter, knowledge of how to construct and lead discussion using these tools is paramount towards promoting meaningful interaction. The critical factor is that the interaction promoted is a dialogue i.e. a two-way exchange, where learners are provided with feedback in order to take action (Laurillard, 2002). It is through this type of iterative process that learners are believed to deepen their knowledge. Such interactions rely heavily on the skill and competence of the tutor to design quality discussions (Blanchette, 2011) that allow tutor and learner to interact in a deep and iterative way.

The pedagogical beliefs of the tutor are also important. Being conversant with the online learning tools technology and comfortable in leading discussion does not ensure that deep discussion will be engaged in by all participants. Brookfield and Preskill (2005) suggest that if the tutor's pedagogical beliefs support the design and implementation of social constructivist learning theories then learners are more likely to engage in deep discussion 'live' online. Thus, from this perspective, discussion 
moves the power away from the tutor to create a more democratic model of learning where the learners take ownership for their learning. Through engaging in this type of discussion, participants stay focused on the topic, offer evidence to support their point of view (or explain the basis for that view), recall and summarise some of the multiple viewpoints that have been shared, attempt to identify connections between contributions already made and show how the discussion has changed their thinking or added to their knowledge. In short, they are able to contribute to the creation of new knowledge. In order to design and maintain such critical discussions with their learners Brookfield and Preskill (2005) identified nine dispositions that tutors need to develop, so they and their learners can engage in deep knowledge construction. Therefore, the tutor has a critical role to play in structuring and "scaffolding" the types of interactions that take place online (e.g. Rovai, 2004).

Yet, the learner too has a key role to play in such settings as they need to take responsibility for their own learning and engage constructively with the tutor and their peers (Anderson and Garrison, 1998). Learners can sometimes become frustrated with discussion viewing it as a waste of their time (Brookfield and Preskill, 2005). While other learners may be considered "lurkers" (Salmon, 2000) having "low" or "no visibility" (Beaudoin, 2002, in Gulati, 2004) resulting in 'silence' online, particularly in synchronous discussions when students are not actively participating.

Thus, tutors need to be aware that student silence may be an indication of other feelings such as a lack of confidence or trust to share a view or an opinion. It is at times like this that tutors need to consider how they can create an a democratic classroom where everyone is encouraged to participate and where it is acceptable to remain silent. This type of democratic participation is encapsulated in a teacher education context in the Fully Online Learning Community Model (FOLC) described by Blayone, vanOostveen, Barber, DiGiuseppe and Childs (2017) that builds on the Community of Inquiry (COI) model, which underpins contemporary approaches to the design of distance education, including MOOCs. This model also underscores the importance of teacher presence and rich and meaningful interactions as the basis of deep learning.

In summary, the literature on synchronous online learning suggests that the role of the tutor in designing and enabling meaningful interactions and discussion is essential. It also suggests that their pedagogical beliefs and their technical knowledge of the online technologies are key to ensuring deep discussions. However, there is limited evidence that synchronous online learning tools on their own without skilful facilitation and intervention by tutors can recreate welcome and safe places for learners to engage in open deliberation.

\section{Design \& Development of the 21CLD MOOC}

To address the identified gap in the literature regarding synchronous online learning, and the potential of MOOCs as a means of scaling the model of teacher professional learning, funding was secured from Microsoft to design an online course. Working with a partner in the sector (H2 Learning), the intention was to develop a MOOC that would challenge and enable teachers to examine and change their own classroom 
practices, as they relate to innovative uses of digital technologies to support their own and their students' learning and the development of $21^{\text {st }}$ century skills.

In keeping with Phase 1 and 2, a central feature underpinning the MOOC design was the tenet that it is teachers' understanding of $21^{\text {st }}$ century skill requirements that influences the ways in which they use ICT (e.g. Shear et al., 2011). As previously established, when teachers' pedagogical orientations are underpinned by understandings of $21^{\text {st }}$ century learning, they take on a more facilitative role, provide student-centered guidance and feedback, and engage more frequently in exploratory and team-building activities with students. Findings in Phase 1 and 2 were that the change in teachers' pedagogical orientation and the emergence of a culture of selfevaluation was directly attributed to the use of the Learning Activity/Student Work (LASW) framework and the deep discussions they engaged in around their classroom practice. To this end, rooted in the LASW Framework, (now called $21^{\text {st }}$ Century Learning Design (21CLD), an eight-module, self-directed course was designed and developed over a nine month duration as a core component of the MOOC design. The modules explore what learning looks like in the $21^{\text {st }}$ century and how innovative teaching practices can support student learning to develop the key $21^{\text {st }}$ skills of collaboration, knowledge construction, self-regulation, problem-solving and innovation, skilled communication, and the use of ICT for learning. As well as defining, explaining and illustrating each of the skills, an integral part of each module is an 'in action' video in which teachers from across the world showcase how they have embedded a specific skill in their classroom. Each of thirteen teachers from countries such as Finland, Canada, South Africa and Australia have designed extended learning units for their students which focus on the development of $21^{\text {st }}$ century skills while also embedding the use of a range of digital technologies.. Feedback, mentoring and support was provided by the design team (Butler, Leahy \& $\mathrm{H} 2$ ) on these learning units and the teachers were provided with hand-held cameras to capture the development of the learning process. Working with this footage, the design team then constructed a comprehensive "in action" video for each of the key $21^{\text {st }}$ century skills.

As mentioned previously, Laurillard (2016) speaks of the need to design opportunities for more collaborative and constructivist engagement with teachers to promote "co-learning" (p.3). To this end, we have embedded focused questions related to the design of learning activities into each MOOC module. However, to promote meaningful co-learning, we are aware of the need to challenge and support teachers as they engage in critical discussions around their understandings and classroom experiences of 21CLD in action. We know from Phase 1 and 2 that such discussions shifted teachers' pedagogical orientation and are a key element of the job embedded professional learning model which are readily supported through face-toface interactions. Drawing on the literature outlined earlier in this paper, the challenge now is to embed these critical discussions in a MOOC environment. This challenge raises a number of further questions. What type of design is required in order to promote critically reflective dialogue through asynchronous online discussion? To what extent will asynchronous discussion fora need to be moderated and supported by other means such as synchronous "live" sessions? 


\subsection{Designing opportunities for online deep learning conversations}

Currently, any teacher can access the MOOC assets developed in Phase 3 of the initiative for the eight modules of the 21CLD course on the Microsoft Educator Platform. Within five months of its launch in February 2016 over 10,500 have participated in the modules and it is still consistently in the top 10 courses on the Microsoft Educator Platform. However, the content has not, as yet, been designed or hosted on a MOOC platform which would lend towards a more blended model of professional learning.

The next phase of development is therefore to take these assets and to relocate them on an intentionally designed MOOC platform where we can build learner experiences to recreate the deep professional learning experiences observed in Phase $1 \&$ Phase 2 . To this end the University has recently made the decision to join the FutureLearn platform which in terms of its design was strongly influenced by Laurillard's Conversation Framework (2002). However, the challenge remains to design the social supports within the MOOC structure to sustain the collaboration, dialogue and ongoing reflection that is necessary for the changes in pedagogical orientation and classroom practices. In particular, we need to establish if the technology exists and, if so, how to successfully embed it in the teaching and learning experience to support the deep engagement we witnessed in Phase 1 and 2.

Cognisant of our experiences in Phase 1 and 2, we strove to design a MOOC that could reach large numbers while also providing opportunities for teachers to learn through practice, discussion and production (Laurillard, 2016). In this sense, we wanted teachers both to try out ideas in their classrooms and report back on their experience. We wanted to promote critical reflection and discussion as well as providing opportunities for teachers to share ideas and resources. Incorporating these elements would, we believed, result in scaling the model of teacher professional learning we had developed to date that is contextualised and meaningfully rooted in classroom practice. We are critically aware that a community of practice needs to be built around a MOOC, as opposed to individuals just working through the content on their own. The challenge as we begin to design the next iteration of the 21CLD MOOC is to explore if we can recreate the collaborative nature of peer-coaching and develop the communities of practice that can sustain a culture of self-evaluation. Given that professional learning is most effective when it is grounded in collective discussions of classroom practice (Warren Little, 2003) our major concern is how can we recreate in an online environment those deep learning conversations which centred on teachers' classroom practices that were central to teacher learning in Phase $1 \& 2$. Therefore, in the next iteration of the 21CLD MOOC we want to explore if the synchronous online learning tools are up to the job of facilitating deep deliberation, as defined by Brookfield and Preskill (2005). We know, from Phase 1 and 2, that such deep deliberation is an essential component of an effective professional learning model. Thus, the only variable we are changing from Phase 1 and 2 is the medium through which we engage in deep discussion, moving from face-to-face to online and we want to explore if and how synchronous online learning tools can support such interaction. 


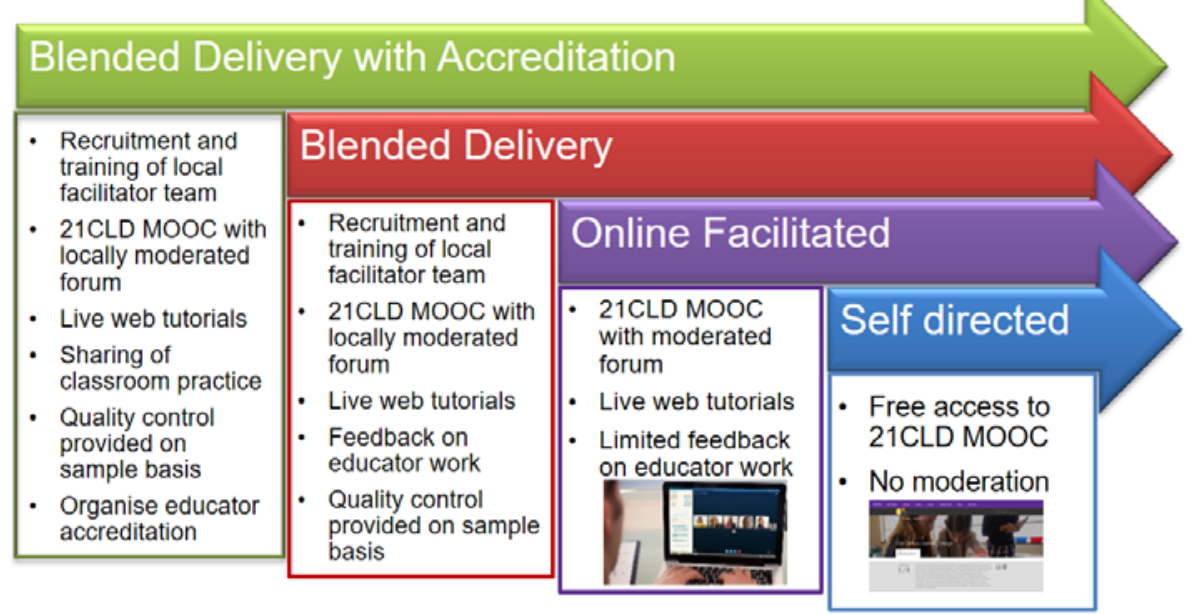

Figure 1: Possible ways that the 21CLD MOOC can be developed

We are aware of the centrality of the role of the online tutor and the development of certain critical "dispositions" (Brookfield and Preskill, 2005) so that participants will be able to engage in intense, debate and dialogue. In this case the disposition of deliberation appears particularly relevant as we want to provide teachers with an opportunity to engage in robust debate around their teaching practices, "to discuss issues as fully as possible by offering arguments and counterarguments that are supported by evidence, data, and logic and by holding strongly to these unless there are good reasons not to do so" (Brookfield and Preskill, 2005, p. 13). This allows all to engage in robust debate where all views are valued. Deliberation has very much been to the fore in Phase $1 \& 2$ with teachers engaged in robust discussion embedded in their classroom practices.

The literature also suggests that the facilitators' pedagogical beliefs and their technical knowledge of the online technologies are key to ensuring deep discussions. To this end for the initial pilot phase, the authors will be the facilitators using synchronous online learning tools to facilitate deep discussion with the 21CLD MOOC assets by working with a group of teachers in the southwest of Ireland recruited by the local teacher Education Centre. However, a basic assumption of this so-called $4^{\text {th }}$ wave is that a one-size model of online professional learning will not fit all and that different strokes will be needed for different folks depending on the educational context (Picciano, 2014). Consequently, in addition to this pilot we are continuing to explore other possible ways the 21CLD MOOC can be developed, as illustrated in Figure 1.

A blended delivery model may be worthy of further development in our efforts to scale up the professional learning model, and to this end we have developed an accredited post-graduate certificate and diploma which is scheduled to begin in January 2018. 


\section{Conclusion}

In conclusion, this paper has discussed a range of conceptual, theoretical and practical considerations around the potential of MOOCs for scaling up teacher professional learning. In addition, and in keeping with "the cMOOCs focus on community building, social interaction [and] peer review" (Jobe et al., 2014, p.1581), we want participants to be able to work in peer groups, sharing experiences, ideas and expertise. This type of MOOC design also aligns with our job embedded approach that recognises the value of the experience and expertise that teachers can offer each other (Butler \& Leahy, 2015). Although with the support of Microsoft, the 21CLD resources are now available to a world-wide audience, we have still to develop ways that the school-embedded, job-focused model of teacher professional learning can be scaled effectively so that the teacher professional learning experience is contextualised and rooted in classroom practice. If the next stage is successful and we can recreate the deep discussions about learning online, our logical next step would include the identification of cohorts of teachers at local and regional levels that would be capable of supporting others. In this way, we would be recreating in an online environment the collaborative nature of peer coaching and developing communities of practices that would sustain a culture of self-evaluation similar to that which occurred in Phase1 and 2. We propose to trial this approach in Ireland in 2017 by working with the national network of teacher education centres.

\section{References}

1. Abrami, P. C., Bernard, R. M., Bures, E. M., Borokhovski, E. and Tamim, R. M. (2011). 'Interaction in distance education and online learning: using evidence and theory to improve practice'. Journal of Computing in Higher Education, 23, 82-103.

2. Ananiadou, K. \& Claro, M. (2009). 21st Century Skills and competences for New Millennium learners in OECD countries. Organization for Economic Cooperation and Development. EDU Working paper no. 41.

3. Anderson, T. and Garrison, D. R. (1998). 'Learning in a networked world: New roles and responsibilities'. In C. Gibson (Ed.), Learners in Higher Education (pp. 97-112). Madison, WI: Atwood Publishing.

4. Bannan-Ritland, B. (2002). 'Computer-Mediated Communication, Elearning and Interactivity: A Review of the Research'. The Quarterly Review of Distance Learning, 3 (2), 161-179.

5. Binkley, M., Erstad, O., Herman, J., Raizen, S., Ripley, M., Miller-Ricci, M., \& Rumble, M. (2012). Defining twenty-first century skills. In P. Griffin, B. McGaw and E. Care (Eds.), Assessment and teaching of 21st century skills (pp. 17-66). Springer Netherlands.

6. Blanchette, J. (2011). 'Participant interaction in asynchronous learning environments: Evaluating interaction analysis methods'. [Online]. Linguistics and Education. Available at: www.elsevier.com/locate/linged.

7. Blayone, T., vanOostveen, R., Barber, W., DiGiuseppe, M., \& Childs, E. (2017). Democratizing digital learning: Theorizing the fully online learning community model. International Journal of Educational Technology in Higher Education, 14 (13), 1-16. 
8. Bower, M, Dalgarno, B., Kennedy, G., Lee, M., \& Kenney, J. (2014). Blended synchronous learning handbook. Australian Office for Learning and Teaching. Available from https://blendsync.org/handbook.

9. Brookfield, S. and Preskill, S. (2005). Discussion as a way of teaching. (Vol. 2). San Francisco: Jossey-Bass.

10. Butler, D. (2004). Self-determined Teacher Learning in a Digital Context: Fundamental Change in Thinking and Practice. Unpublished doctoral thesis, Dublin City University.

11. Butler, D. \& Leahy, M. (2015). "Moving towards innovation: The development of a sustainable framework for teacher professional learning” in Shaping the Future: How technology can lead to educational transformation.

12. Darling-Hammond, L. (1993). Reframing the school reform agenda: Developing capacity for school transformation. Phi Delta Kappan, 74(12), 752-61.

13. DES (2015). Digital Strategy for Schools - 2015-2020. Available at: https://www.education.ie/en/Publications/Policy-Reports/Digital-Strategy-for-Schools2015-2020.pdf.

14. Downes, S. (2012) Massively Open Online Courses are here to stay, Stephen’s Web, July 20

15. Ebben, M., \& Murphy, J. S. (2014). Unpacking MOOC scholarly discourse: a review of nascent MOOC scholarship. Learning, Media and Technology, 39(3), 328-345.

16. ETA (European Training Agency). (2010). Key Competences. [Online].

17. Greene, J. A., Oswald, C. A., \& Pomerantz, J. (2015). Predictors of retention and achievement in a massive open online course. American Educational Research Journal, 0002831215584621.

18. Garrison, R. D. and Cleveland-Innes, M. (2005). 'Facilitating Cognitive Presence in Online Learning: Interaction is not Enough'. American Journal of Distance Education, 19 (3), 133148.

19. Gulati, S. (2004). Constructivism and emerging online learning pedagogy: a discussion for formal to acknowledge and promote the informal, Annual Conference of the Universities Association for Continuing Education - Regional Futures: Formal and Informal Learning Perspectives. Centre for Lifelong Learning, University of Glamorgan.

20. Hallissy, M. (2014) Building teacher professionalism in teaching-learning interactions between online tutors and learners during synchronous tutorials - a case study from Hibernia College. EdD, Institute of Education [Online] Available at: https://www.academia.edu/9427758/Building_teacher_professionalism_in_teachinglearning_interactions_between_online_tutors_and_learners_during_synchronous_tutorials _a_case_study_from_Hibernia_College).

21. Hirumi, A. (2002). 'A Framework for Analysing, Designing, and Sequencing Planned eLearning Interactions'. The Quarterly Review of Distance Learning, 3 (2), 141-160.

22. Hodges, C., Lowenthal, P., \& Grant, M. (2016). Teacher Professional Development in the Digital Age: Design Considerations for MOOCs for Teachers. In Society for Information Technology \& Teacher Education International Conference (pp. 2089-2096).

23. ICEF Monitor. (2016). MOOC enrolment surpassed 35 million in 2015. Available at: http://monitor.icef.com/2016/01/mooc-enrolment-surpassed-35-million-in-2015.

24. Jobe, W., Östlund, C., \& Svensson, L. (2014). MOOCs for professional teacher development. In Society for Information Technology \& Teacher Education International Conference, Mar 17, 2014 in Jacksonville, Florida, United States (pp. 1580-1586). AACE.

25. Laurillard, D. (2002). Rethinking University Teaching: A conversational framework for the effective use of learning technologies. (Second Ed.). London and New York: Routledge Falmer. 
26. Laurillard, D. (2016). The educational problem that MOOCs could solve: professional development for teachers of disadvantaged students. Research in Learning Technology. Available at http://dx.doi.org/10.3402/rlt.v24.29369.

27. Law, N., \& Chow, A. (2008). Pedagogical orientation in mathematics and science and the use of ICT. In Law, N., Pelgrum, J. \& Plomp, T. (2008). Pedagogy and ICT use in schools around the world: Findings from the IEA SITES 2006 study. Hong Kong: The Comparative Education Research Centre.

28. NCCA (National Council for Curriculum and Assessment). (2009). Senior cycle key skills framework. Dublin:

29. National Foundation for the Improvement of Education (1996). Teachers take charge of learning: Transferring professional development for student success. Available at: http://files.eric.ed.gov/fulltext/ED401251.pdf.

30. Organisation for Economic Cooperation and Development (OECD). (2005). The definition and selection of key competencies. Paris: Author. Available at: http://www.oecd.org/document/17/0,3343,en_2649_39263238_2669073_1_1_1_1,00.html

31. Park, Y. J., \& Bonk, C. J. (2007). Synchronous learning experiences: Distance and residential learners' perspectives in a blended graduate course. Journal of Interactive Online Learning, 6(3), 245-264.

32. Picciano, A. (2014). A critical reflection of the current research in online and blended learning. ELM Magazine, Theme Issue, Issue 4/2014. Available at:

http://www.elmmagazine.eu/articles/a-critical-reflection-of-the-current-research-in-onlineand-blended-learning.

33. Rovai, A. P. (2004). 'A constructivist approach to online college learning'. Internet and Higher Education, 7 (2), 79-93.

34. Salmon, G. (2000). E-moderating: The Key to Teaching and Learning Online. London: Kogan Pagan.

35. Shear, L., Means, B., Gorges, T., Toyama, Y., Gallagher, L., Estrella, G., \& Lundh, P. (2009). The Microsoft Innovative Schools Program Year 1 evaluation report. Seattle: Microsoft.

36. Shear, L., Gallagher, L., \& Patel, D. (2011). ITL Research: Evolving educational ecosystems. Redmond, WA: Microsoft.

37. Vivian, R., Falkner, K., \& Falkner, N. (2014). Addressing the challenges of a new digital technologies curriculum: MOOCs as a scalable solution for teacher professional development. Research in Learning Technology, 22.

38. Warren Little, J. (2003). Inside teacher community: Representations of classroom practice. Teachers College Record, 105(6), pp. 913-945 